\title{
Selectivity in Ketenimine Cycloadditions. Photoelectron HeI Spectra of Ketenimines
}

\author{
Fernando Bernardi and Andrea Bottoni \\ Istituto di Chimica Organica dell'Università, Viale Risorgimento, Bologna, Italy, \\ Arturo Battaglia and Giuseppe Distefano \\ Laboratorio dei Composti del Carbonio Contenenti Etero atomi e loro Applicazioni del C.N.R., \\ Ozzano-Emilia, Bologna, Italy, \\ and
}

Alessandro Dondoni

Laboratorio di Chimica Organica, Facoltà di Scienze, Università, Ferrara, Italy

Z. Naturforsch. 35a, 521-525 (1980); received March 15, 1980

\begin{abstract}
The first few bands in the photoelectron (HeI) spectra of ketenimines $\mathrm{R}^{1} \mathrm{R}^{2} \mathrm{C}=\mathrm{C}=\mathrm{NR}^{3}$ ( $\mathrm{R}^{1}, \mathrm{R}^{2}=\mathrm{H}, \mathrm{CH}_{3}, \mathrm{C}_{5} \mathrm{H}_{6}, \mathrm{CH}_{2}=\mathrm{CH} ; \mathrm{R}^{3}=$ alkyl or aryl group) are assigned to the corresponding molecular orbitals. The assignment is based on SCF-MO calculations made at three different levels (CNDO/2, ab-initio STO-3G and 4-31G) coupled with perturbational molecular orbital analyses.

The $\pi$-orbitals of the unsaturated substituents are found to interact with one of the two perpendicular $\pi$-electron systems of the $>\mathrm{C}=\mathrm{C}=\mathrm{N}$ - residue, the critical factor being the position of attack of the substituent.

The relevance of these results on the site selectivity observed in cycloaddition reactions of these species is discussed.
\end{abstract}

\section{Introduction}

Cycloadditions by double or triple bond systems to ketenimines occur at different sites of the cumulene and may even involve unsaturated centres of groups flanking carbon or nitrogen of the cumulative system. The site selectivity depends on the nature of the substituents on the cumulene and the electrondonor or acceptor characteristics of the other partner as well. For instance, 1,2-cycloaddition across the cumulene $\mathrm{C}=\mathrm{C}$ bond of various ketenmines to give four-membered $1: 1$ adducts occurs in thiobenzophenones [1], nitrosobenzenes [2], ketones [3], isocyanates [4], and azobenzenes [5], while reaction across the $\mathrm{C}=\mathrm{N}$ bond occurs in an ynamine [6] and a ketene acetal [7]. Furthermore, 1,4cycloadditions to give six-membered $1: 1$ adducts may also occur. These involve the $\mathrm{C}=\mathrm{N}$ bond of the cumulene and the $\mathrm{C}=\mathrm{C}$ bond of an aryl group attached to nitrogen as observed for reactions between $\mathrm{N}$-aryl ketenimines with thiobenzophenones [1], vinyl ethers [7], and ynamines [8], or the

Reprint requests to Dr. G. Distefano, Laboratorio dei Composti del Carbonio Contenenti Etero atomi e loro Applicazioni del C.N.R., Ozzano-Emilia, Bologna/Italien.
$\mathrm{C}=\mathrm{C}$ bond of the cumulene and that of an ethylenic system flanking the terminal carbon of the cumulene as observed for reactions between vinyl ketenimines and various electron-deficient dienophiles [8] such as dimethylacetylenedicarboxylate, tetracyanoethylene, 1,1-dicyanostyrene, and maleic anhydride.

The variable site selectivities of ketenimine cycloadditions are therefore, a versatile stereospecific method for the synthesis of four- and six-membered ring systems. However, the origin of the varying stereochemistry and, likely, of the mechanism has not been completely clarified.

A detailed knowledge of the electronic structure of these molecules can certainly provide useful information for the solution of this problem. To this aim, we have carried out an ultraviolet photoelectron (HeI) spectroscopic study of some representative ketenimines of the type $\mathrm{R}^{1} \mathrm{R}^{2} \mathrm{C}=\mathrm{C}=\mathrm{NR}^{3}$ (Table 1 ).

\section{Experimental}

The ultraviolett photoelectron (UPS) spectra were recorded on a Perkin-Elmer PS 18 photoelectron spectrometer. The HeI resonance line at $584 \AA$ $(21.22 \mathrm{eV})$ served as the ionization source. The spectra were calibrated against $\mathrm{Ar}$ and Xe lines. The

0340-4811 / $80 / 0500-0521 \$ 01.00 / 0$. - Please order a reprint rather than making your own copy. 
Table 1. Ionization energy values $(\mathrm{eV})$ and corresponding $\mathrm{MO}$ 's ${ }^{\mathrm{a}}$ for various ketenimines.

\begin{tabular}{|c|c|c|c|c|c|c|c|}
\hline $\begin{array}{l}\text { Keten- } \\
\text { imine }\end{array}$ & $\mathrm{R}^{1}$ & $\mathrm{R}^{2}$ & $\mathrm{R}^{3}$ & $I_{1}$ & $I_{2}$ & $I_{3}$ & $I_{4}$ \\
\hline 1 & $\mathrm{CH}_{3}$ & $\mathrm{CH}_{3}$ & Cyclohexane & $7.85\left(\pi^{-}\right)$ & & & \\
\hline $2 \mathrm{a}$ & $\mathrm{CH}_{3}$ & $\mathrm{CH}_{3}$ & $\mathrm{C}_{6} \mathrm{H}_{5}$ & $8.02\left(\pi^{-}\right)$ & $8.88\left(\pi^{-^{\prime}}-\pi_{\mathrm{S}}\right)$ & $9.35\left(\pi_{\mathrm{a}}\right)$ & \\
\hline $2 \mathrm{~b}$ & $\mathrm{CH}_{3}$ & $\mathrm{CH}_{3}$ & $p-\mathrm{CH}_{3}-\mathrm{C}_{6} \mathrm{H}_{4}$ & $7.92\left(\pi^{-}\right)$ & $8.55\left(\pi^{-^{\prime}}-\pi_{\mathrm{S}}\right)$ & $9.18\left(\pi_{\mathrm{a}}\right)$ & \\
\hline $2 \mathrm{c}$ & $\mathrm{CH}_{3}$ & $\mathrm{CH}_{3}$ & $m-\mathrm{CH}_{3}-\mathrm{C}_{6} \mathrm{H}_{4}$ & $7.96\left(\pi^{-}\right)$ & $8.75\left(\pi^{-\prime}-\pi_{\mathrm{S}}\right)$ & $9.00\left(\pi_{\mathrm{a}}\right)$ & \\
\hline $2 d$ & $\mathrm{CH}_{3}$ & $\mathrm{CH}_{3}$ & $p-\mathrm{OCH}_{3} \mathrm{C}_{6} \mathrm{H}_{4}$ & $7.83\left(\pi^{-}\right)$ & $8.20\left(\pi^{-^{\prime}}-\pi_{\mathrm{S}}\right)$ & $9.21\left(\pi_{\mathrm{a}}\right)$ & \\
\hline $2 \mathrm{e}$ & $\mathrm{CH}_{3}$ & $\mathrm{CH}_{3}$ & $o, o^{\prime}\left(\mathrm{CH}_{3}\right)_{2} \mathrm{C}_{6} \mathrm{H}_{3}$ & $7.75\left(\pi^{-}\right)$ & $8.63\left(\pi^{-\prime}-\pi_{\mathrm{s}}\right)$ & $8.85\left(\pi_{\mathrm{a}}\right)$ & \\
\hline $3 a$ & $\mathrm{H}$ & $\mathrm{C}_{6} \mathrm{H}_{5}$ & Cyclohexane & $7.60\left(\pi^{-}-\pi_{\mathrm{S}}\right)$ & $9.03\left(\pi_{\mathrm{a}}\right)$ & $9.70\left(\pi^{-}+\pi_{\mathrm{s}}\right)$ & \\
\hline $3 \mathrm{~b}$ & $\mathrm{H}$ & $\mathrm{C}_{6} \mathrm{H}_{5}$ & $t-\mathrm{But}$ & $7.65\left(\pi^{-}-\pi_{\mathrm{s}}\right)$ & $9.10\left(\pi_{\mathrm{a}}\right)$ & $9.68\left(\pi^{-}+\pi_{\mathrm{S}}\right)$ & \\
\hline $3 \mathrm{c}$ & $\mathrm{H}$ & $\mathrm{C}_{6} \mathrm{H}_{5}$ & $\mathrm{CH}_{3}$ & $7.79\left(\pi^{-}-\pi_{\mathrm{s}}\right)$ & $9.12\left(\pi_{\mathrm{a}}\right)$ & $9.91\left(\pi^{-}+\pi_{\mathrm{S}}\right)$ & \\
\hline 4 & $\mathrm{C}_{6} \mathrm{H}_{5}$ & $\mathrm{C}_{6} \mathrm{H}_{5}$ & $\mathrm{CH}_{3}$ & $7.40\left(\pi^{-}-\pi_{\mathrm{s}^{+}}\right)$ & $8.93\left(\pi_{\mathrm{a}}\right)$ & $9.15\left(\pi_{\mathrm{s}}^{-}\right)$ & $9.80\left(\pi^{-}+\pi_{\mathrm{s}}{ }^{+}\right)$ \\
\hline $5 a$ & $\mathrm{CH}_{3}$ & $\mathrm{H}_{2} \mathrm{C}=\mathrm{CH}$ & $p-\mathrm{CH}_{3}-\mathrm{C}_{6} \mathrm{H}_{4}$ & $7.73\left(\pi^{-}-\pi\right)$ & $8.55\left(\pi^{-\prime}-\pi_{\mathrm{s}}\right)$ & $9.23\left(\pi_{\mathrm{a}}\right)$ & $10.24\left(\pi^{-}+\pi\right)$ \\
\hline $5 \mathrm{~b}$ & $\mathrm{CH}_{3}$ & $\mathrm{H}_{2} \mathrm{C}=\mathrm{CH}$ & $m, m^{\prime}\left(\mathrm{CH}_{3}\right)_{2} \mathrm{C}_{6} \mathrm{H}_{3}$ & $7.73\left(\pi^{-}-\pi\right)$ & $8.59\left(\pi^{-\prime}-\pi_{\mathrm{s}}\right)$ & $8.77\left(\pi_{\mathrm{a}}\right)$ & $10.27\left(\pi^{-}+\pi\right)$ \\
\hline
\end{tabular}

a For symbols, see text.

accuracy of the ionization energy values (IE) is estimated to be $\pm 0.05 \mathrm{eV}$.

Ketenimines $1-4$ were prepared as described alsewhere [ $1 \mathrm{~b}]$. Vinylketenimines $5 \mathrm{a}$ and $5 \mathrm{~b}$ were obtained from the corresponding amides by the $\mathrm{Ph}_{3} \mathrm{P} / \mathrm{Br}_{2} / \mathrm{Et}_{3} \mathrm{~N}$ method of Bestmann et al. [9]. Compound 5 a had the same characteristics as described by Ghosez [8]; ketenimine $5 \mathrm{~b}$ was a yellow oil: b.p. $70^{\circ}$ at $0.1 \mathrm{~mm} \mathrm{Hg}$, IR $\left(\mathrm{CCl}_{4}\right) 2000 \mathrm{~cm}^{-1}$ $(\mathrm{C}=\mathrm{C}=\mathrm{N}),{ }^{1} \mathrm{H}$ NMR $(90 \mathrm{MHz}, \delta$ from TMS in $\left.\mathrm{CCl}_{4}\right) 1.87\left(\mathrm{~s}, 3 \mathrm{H}\right.$ allylic), $2.30\left(\mathrm{~s}, 6 \mathrm{H}\right.$ of $\mathrm{CH}_{3}$ arom.), 4.83 (d, 1 vinyl $\mathrm{H}$ ), 4.86 (d, 1 vinyl $\mathrm{H}$ ), $6.83\left(\mathrm{dd}, \quad \mathrm{CH}=\mathrm{CH}_{2}, \quad \mathrm{~J}_{\text {cis }}=10.32 \mathrm{~Hz}, \quad \mathrm{~J}_{\text {trans }}=\right.$ $16.8 \mathrm{~Hz}$ ), 6.82 (s, $3 \mathrm{H}$ arom.).

\section{Calculations}

In order to facilitate the correlation of the first few bands of the UPS spectrum of the compounds listed in Table 1 with the corresponding molecular orbitals (MO), we have made use of the results of various SCF-MO computations, as well as of qualitative Pertubational Molecular Orbital (PMO) analyses [10]. We first investigated the model ketenimine $\mathrm{H}_{2} \mathrm{C}=\mathrm{C}=\mathrm{NH}$ whose geometry was optimized at the ab-initio SCF-MO STO-3G level [11]. The stable structure and the optimum values of the various geometrical parameters are reported in the scheme.

These parameters agree with those reported by Ghosez and O'Donnell [12] and compare favourably with those obtained by X-ray diffraction [13] for two $\mathrm{N}$-aryl-2,2-diphenyl ketenimines when the limitations of the basis set are taken into account. We have also carried out at the previously optimized
Scheme<smiles>[1H]C=C=NC</smiles>

BOND LENGTHS ( $(\AA)$

BOND ANGLES

$R\left(C, C_{2}\right)=1.294$

$R\left(C_{2} N\right)=1.243$

$\mathbf{R}\left(\mathrm{C}_{1} \mathrm{H}_{1}\right)=\mathbf{R}\left(\mathrm{C}_{1} \mathrm{H}_{2}\right)=1.081$

$\mathbf{R}\left(\mathrm{NH}_{3}\right)=1.050$

$\begin{aligned} \angle \mathrm{H}_{1} \mathrm{C}_{1} \mathrm{C}_{2}= & \angle \mathrm{H}_{2} \mathrm{C}_{1} \mathrm{C}_{2}=121.0^{\circ} \\ & \angle \mathrm{H}_{3} \mathrm{~N} \mathrm{C}_{2}=111.0^{\circ}\end{aligned}$

geometry an ab-initio SCF-MO computation at the 4.31G level [14] and a CNDO/2 computation [15]. The orbital energy values of the four highest occupied MO's at the three different levels are listed in Figure 1. It can be noticed that, with respect to the $4-31 \mathrm{G}$ values that usually reproduce satisfactorily the experimental IE's, the STO-3G values are con-

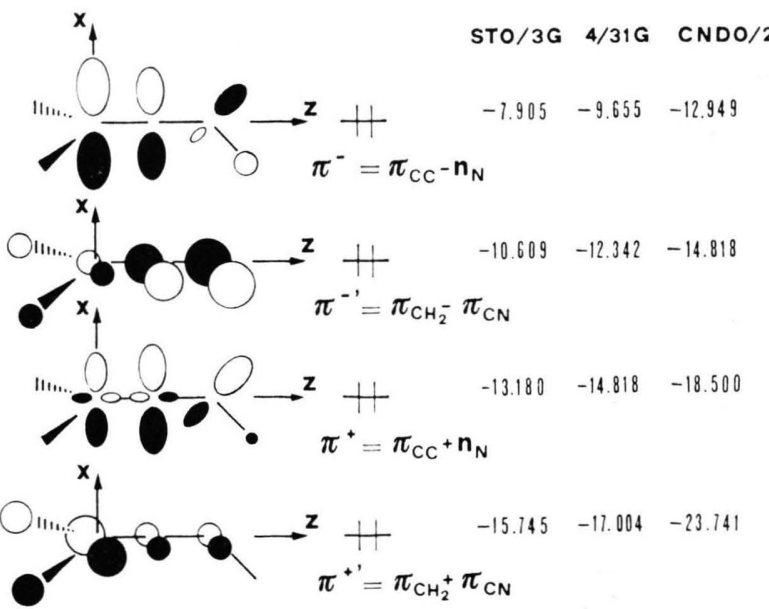

Fig. 1. Four highest occupied MO's of the model ketenimine $\mathrm{H}_{2} \mathrm{C}=\mathrm{C}=\mathrm{NH}$, together with associated orbital energies computed at three different levels. 
siderably higher, but show the same ordering. These MO's show the most peculiar feature of these compounds, i.e. the presence of $\pi$-electron systems adjacent to each-other. Two MO's, the highest occupied MO (HOMO) and the third one, arise from the out-of-phase and in-phase combinations of the $\pi$-MO of the $\mathrm{C}=\mathrm{C}$ unit with the nitrogen lone pair orbital and will be denoted here as $\pi^{-}$and $\pi^{+}$, respectively. The other two MO's, i.e. the second and the fourth ones, arise from the out-of-phase and in-phase combinations of the $\pi$-MO's of the $\mathrm{CH}_{2}$ and $\mathrm{C}=\mathrm{N}$ units and will be denoted here as $\pi^{-\prime}$ and $\pi^{+\prime}$ respectively.

At the CNDO/2 level the orbital energies are significantly lower and, more important, the correct order is found for the first three MO's, while the fourth highest occupied MO is a $\sigma$ MO. Since we are interested here in the analysis of the low IE region of the spectra of the ketenimines $1-5$, we have carried out CNDO/2 computations for some of the molecules, as a guide for the validity of the PMO arguments and for a correct assignment.

\section{Results and Discussion}

We begin our analysis by considering derivative 1 (Table 1) whose spectrum shows an isolated band at $7.85 \mathrm{eV}$ and a broad intense band in the region $10-15 \mathrm{eV}$. (The low IE region of the spectrum of this and other selected compounds are presented in Figure 2.) Therefore, only the first band can be assigned with confidence to ionization from the $\pi^{-}$ MO on the basis of computational results. The effect of substituents such as $\mathrm{R}^{1}=\mathrm{R}^{2}=\mathrm{CH}_{3}$ and $\mathrm{R}^{3}=$ cyclohexyl upon the MO's of the $>\mathrm{C}=\mathrm{C}=\mathrm{N}$ - unit is not expected to alter the ordering computationally
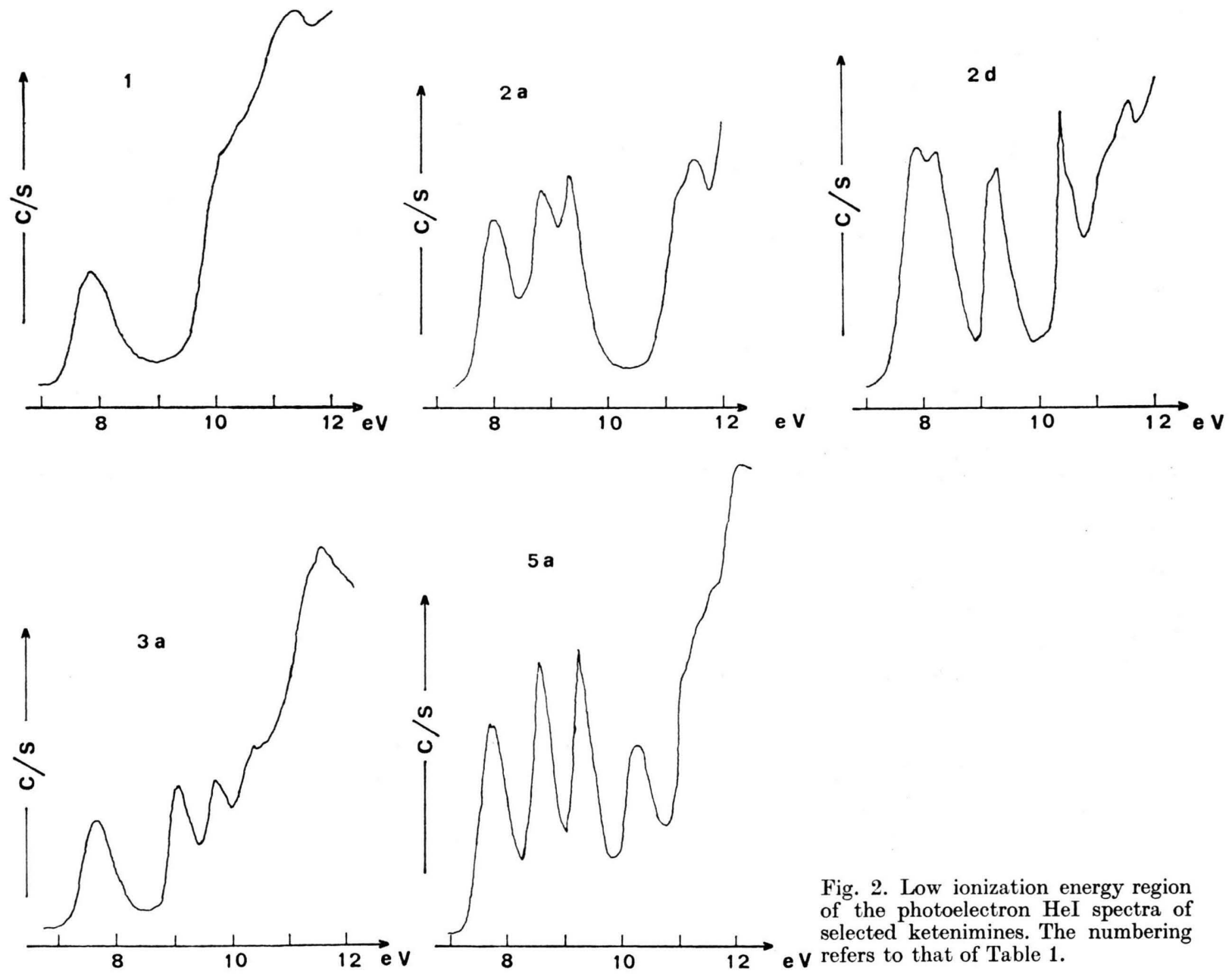
found in the model system for the first highest occupied MO's. The same assignment derives also from the comparison with the spectra of simple related compounds (such as $\left(\mathrm{CH}_{3}\right)_{2} \mathrm{CH}-\mathrm{CH}=$ $\mathrm{N}-\mathrm{C}_{2} \mathrm{H}_{5}$ [16] and $\left(\mathrm{CH}_{3}\right)_{2} \mathrm{C}=\mathrm{CH}_{2}$ [17]).

We consider now the derivatives of type 2 , that differ from compound 1 because the $\mathrm{N}$-cyclohexyl group has been replaced with a phenyl. The extent of the interaction between the MO's of the $>\mathrm{C}=\mathrm{C}=\mathrm{N}-$ unit and those of the phenyl ring depends critically on the conformation assumed by the ring which can rotate around the $\mathrm{N}-\mathrm{C}$ bond. Results from X-ray analyses on similar molecules suggest [13] that the phenyl ring lies in the $\mathrm{xz}$ plane (see Fig. 1). Therefore the $\pi$-MO's of the phenyl ring can not interact with the $\pi^{-}$and $\pi^{+}$ MO's of the ketenimine residue but only with the $\pi^{-\prime}$ and $\pi^{+\prime}$ MO's. Then the HOMO of derivative $2 \mathrm{a}$ is expected to show an IE equal or slightly higher than that of derivative 1 . The first IE of derivative $2 \mathrm{a}$ is $8.02 \mathrm{eV}$, which we assign again to the ionization process from the $\pi^{-}$MO of the ketenimine residue. The second IE can be assigned to the ionization process from the MO arising from the out-of-phase combination of the symmetric $\pi$ MO of the phenyl ring $\left(\pi_{\mathrm{s}}\right)$ with the $\pi^{-\prime}$ MO of the ketenimine residue. These assignments are also in agreement with the $\mathrm{CNDO} / 2$ results. According to these calculations next there are two almost degenerate MO's; one the antisymmetric $\pi$-MO of the phenyl ring $\left(\pi_{\mathrm{a}}\right)$, and the other an MO arising from the combination of $\pi^{-}$with a $\sigma$-MO of the phenyl ring. We have already pointed out that the presence of a $\sigma-\mathrm{MO}$ at high energy is an artifact of this kind of computation. Therefore we assign the third IE to the $\pi_{\mathrm{a}}$ MO.

The effect of the various phenyl substituents upon the IE's is that expected on the basis of their electronic character and is small on the first and third IE's and more pronounced on the second one. This provides additional evidence for the proposed assignment.

Compound 3 a differs from derivative 1 because it contains an $\mathrm{H}$ and a phenyl group bonded to $\mathrm{C}^{1}$ instead of two methyl groups. Again the phenyl ring can rotate and the extent of the interaction between the MO's of the $\mathrm{C}_{6} \mathrm{H}_{5}-$ and $-\mathrm{HC}=\mathrm{C}=\mathrm{NR}$ moieties depends on the conformation assumed by the phenyl ring, that is unknown. If the phenyl ring lies in the plane containing the ${ }^{\mathrm{H}} \backslash \mathrm{C}-\mathrm{C}-\mathrm{N}$ group, then the HOMO of this group will be destabilized because of its interaction with the $\pi_{\mathrm{s}} \mathrm{MO}$ of the phenyl group. On the other hand, if the phenyl ring is significantly rotated, the HOMO will be affected only slightly. The value of $7.60 \mathrm{eV}$ for the first IE indicates a significant destabilization of the HOMO, compared with compound 1 , and therefore the phenyl ring appears to be coplanar with the $\mathrm{H}$

$\mathrm{C}-\mathrm{C}-\mathrm{N}$ moiety and we assign this IE to the $\pi^{-}-\pi_{\mathrm{s}}$ MO. The second IE can be assigned to the $\pi_{\mathrm{a}} \mathrm{MO}$ of the benzene ring and the third one to the $\pi^{-}+\pi_{\mathrm{s}}$ MO. The variations of these IE values deriving from replacement of a cyclohexyl with a $t$ buthyl or methyl group, are very small especially for $\mathrm{IE}_{2}$, in agreement with the assignment proposed.

An estimate of the IE values of the $\pi$-MO's of the two benzene rings of the $C$-diphenyl derivative 4 in a similar situation can be taken from the spectrum of diphenylmethane [18]. This shows a maximum at $9.12 \mathrm{eV}$ which has been assigned to ionization from the antisymmetric $\pi$-ring orbitals $\left(\pi_{\mathrm{a}}\right)$ and two shoulders at 8.67 and $9.3 \mathrm{eV}$ ascribed to the inphase $\left(\pi_{\mathrm{s}}^{+}\right)$and out-of-phase $\left(\pi_{\mathrm{s}}{ }^{-}\right)$combinations of the symmetric $\pi$-orbitals. Consequently, the bands peaking at $7.40,9.15$ and $9.80 \mathrm{eV}$ are assigned to the three combinations (out-of-phase, non-bonding and in-phase) of the $\pi^{-}$MO of the $>\mathrm{C}=\mathrm{C}=\mathrm{N}-$ unit with the two combinations of the symmetric $\pi$-ring orbitals. The band at $8.93 \mathrm{eV}$, because of its intensity, is assigned to ionization from the degenerate antisymmetric $\pi$-MO's of the phenyl groups. The ordering $\pi_{\mathrm{a}}$ above $\pi_{\mathrm{s}}{ }^{-}$is the same as that observed in thiobenzophenone [19].

Compounds $5 \mathrm{a}$ and $5 \mathrm{~b}$ differs from 2 because a vinyl group instead of a methyl is bonded to $\mathrm{C}^{\mathbf{1}}$. The assignment follows readily, since this replacement is expected to destabilize only the HOMO of the $>\mathrm{C}=\mathrm{C}=\mathrm{N}-\mathrm{Ar}$ moiety and cause the appearance of a new peak around $10.5 \mathrm{eV}$ characteristic of an ethylene $\pi$-MO, while all other MO's should remain almost unchanged. The observed IE's are in agreement with these expectations and consequently we assign the first IE to the $\tau^{-}-\tau \mathrm{MO}$, and the fourth IE to the $\tau^{-}+\pi$ MO, while the assignment of the second and third IE remains the same as for compounds 2 . 


\section{Conclusions}

The results obtained in this study provide accurate values for the first energy levels of some representative ketenimines, as well as the magnitude and trend of the variations caused by substitution. This information can be used to gain a better understanding of the reactivity of these heterocumulenes.

A first general indication is that ketenimines are good $\pi$-donors since in all cases the value of the first IE is quite low. Since the $\pi$-donor ability of the ketenimine increases with the decrease of this value, the data of Table 1 indicate that $C^{1}$-substituents such as $\mathrm{C}_{6} \mathrm{H}_{5}-$ or $\mathrm{CH}_{2}=\mathrm{CH}$ - enhance more the $\pi$ donor ability than a phenyl ring bonded to N. This different effect arises from a different orientation of the main plane of these substituents with respect to the $\backslash \mathrm{C}-\mathrm{C}-\mathrm{N}$ plane: a phenyl ring bonded to the terminal carbons $C^{\mathbf{1}}$ is in fact coplanar, or nearly so, with this plane, while a phenyl ring bonded to nitrogen is perpendicular to it. Consequently, when a phenyl ring is bonded to carbon, its $\pi$-MO's interact with the $\pi$-MO's of the $>\mathrm{C}=\mathrm{C}=\mathrm{N}$ - unit and rise the energy of the HOMO, while the $\pi$-MO's of a phenyl ring bonded to $\mathrm{N}$ can only interact with the $\pi^{\prime}$ MO's of the $>\mathrm{C}=\mathrm{C}=\mathrm{N}$ - unit and have only a negligible effect upon the HOMO. The present results provide also some insight into ketenimine cycloadditions which proceed through a pericyclic process and whose important interactions involve

[1] a) A. Dondoni, A. Battaglia, P. Giorgianni, G. Gilli, and M. Sacerdoti, J. Chem. Soc. Chem Comm. 43, (1977); b) A. Dondoni, A. Battaglia, and P. Giorgianni, submitted for publication; c) A. Dondoni, A. Battaglia, F. Bernardi, and P. Giorgianni, submitted for publication.

[2] G. R. Krow, Angew. Chem. Int. Ed. Engl. 10, 435 (1971).

[3] L. A. Singer and P. D. Barlet, Tetrahedron Lette. 1964, 1887; A. Weidler-Kubanek and M. Litt, J. Org. Chem. 33, 1844 (1968).

[4] Nased-Ud-Din, J. Riegl, and L. Skattebøl, J. Chem. Soc. Chem. Comm. 1973, 271.

[5] M. W. Barker and M. E. Coker, J. Heterocycl. Chem. 4, 155 (1967).

[6] L. Ghosez and C. de Perez, Angew. Chem. Int. Ed. Engl. 10, 184 (1971).

[7] N. P. Gambaryan, Russian Chem. Rev. 45, 630 (1976).

[8] E. Sonveaux and L. Ghosez, J. Amer. Chem. Soc. 95, 5417 (1973).

[9] H. J. Bestmann, J. Lienert, and L. Mott, Liebigs Ann. Chem. 718, 24 (1968). the occupied MO's of the ketenimines. These conditions appear to be both satisfied in the 1,4-cycloaddition between $\mathrm{N}$-phenyl ketenimines and thiobenzophenones [ $1 \mathrm{c}]$. The occupied MO of these ketenimines involved in the dominant reaction should be $\pi^{-\prime}-\pi$ (i. e. the next HOMO) : this suggestion agrees with the present results since the trend of the observed rate constants [1 c] parallels the energy sequence of the $\pi^{-\prime}-\pi$ MO.

The present results can also be employed to give a rationale to the variation of site selectivity in cycloadditions to vinyl ketenimines of type 5 . In fact, it has been observed $[8,20]$ that the sites of attack in these ketenimines tend to shift from $a$ to $b$ as the partner in the cycloaddition reaction tends to<smiles></smiles>

become an increasingly better acceptor. This variation can be rationalized by assuming that, as the partner becomes a better acceptor, there is a parallel increase of the importance of the HOMO of the ketenimine in the control of the reaction. Being the HOMO of derivative 5 localized on the $\mathrm{H}_{2} \mathrm{C}=\mathrm{CH}-\mathrm{C}=\mathrm{C}$ system, the attack as in $b$ prevails.

[10] R. Hoffmann, Accounts Chem. Res. 4, 1 (1971).

[11] W. J. Hehre, R. F. Stewart, and J. A. Pople, J. Chem. Phys. 51, 2657 (1969).

[12] L. Ghosez and M. J. O'Donnell, Pericyclic Reactions Vol. II, Eds. A. P. Marchand and R. E. Lehr, Academic Press, NewYork 1971, Chapter 2.

[13] R. R. Naqvi and P. J. Whatley, J. Chem. Soc. (A), $2053(1970)$.

[14] R. Ditchfield, W. J. Hehre, and J. A. Pople, J. Chem. Phys. 54, 724 (1971).

[15] J. A. Pople and D. L. Beveridge, Approximate Molecular Orbital Theory, McGraw-Hill, NewYork 1970.

[16] D. Vocelle, A. Dargelos, R. Pottier, and C. Sandorfy, J. Chem. Phys. 66, 2860 (1977).

[17] D. C. Frost and J. S. Sandhu, Indian J. Chem. 9, 1105 (1971).

[18] G. Distefano, S. Pignataro, L. Szepes, and J. Borossay, J. Organomet. Chem. 104, 173 (1976).

[19] F. Bernardi, F. P. Colonna, G. Distefano, G. Maccagnani, and G. Spunta, Z. Naturforsch. 33a, 468 (1978).

[20] A. Dondoni, A. Battaglia, and F. Bernardi, unpublished results. 